\title{
TEMPO DISSOLVIDO, TEMPO DO CRIME A ESCRITURA DO CONTEMPORÂNEO DE LEONARDO GANDOLFI
}

\author{
Tiago Lanna Pissolati \\ Universidade Federal de Santa Catarina / CAPES
}

\begin{abstract}
RESUMO
No livro de poemas $A$ morte de Tony Bennett, de Leonardo Gandolfi, é possível reconhecer os traços de uma escritura do contemporâneo. Não apenas por se tratarem de poemas escritos e publicados nos últimos anos, mas pelo fato de trazerem em si as marcas do deslocamento, fragmentação e perda que caracterizam a ideia do contemporâneo segundo Giorgio Agamben. Gandolfi escreve a partir de um processo de composição em que cenas narrativas se imobilizam e se dissolvem, para então se transformarem em poesia. 0 poeta também dá sinais de aproximar o gesto da escrita de um ato criminoso, ao compor um universo poético povoado por assassinos, vítimas, investigadores e espiões. A proposta deste artigo é mergulhar nessa escritura de transgressão e dissolução tendo como disparador o poema "Nosso tempo", de Carlos Drummond de Andrade. A ideia é buscar, a partir da colisão desses textos, a compreensão das formas segundo as quais o contemporâneo se escreve e é escrito na poesia de Leonardo Gandolfi.

PALAVRAS-CHAVE: Poesia brasileira. Tempo presente. Contemporâneo.
\end{abstract}

ABSTRACT
In Leonardo Gandolfi's poetry book $A$ morte de Tony Bennett, it is possible to recognize traces of a writing of the contemporary. Not only because it is a set of poems written and published recently, but for the marks of dislocation, fragmentation and loss that compose the idea of contemporary as understood by Giorgio Agamben. Gandolfi writes though a peculiar process of composition, in which narrative scenes are immobilized and dissolved in order to turn into poetry. The poet also attempts to bring the gesture of writing close to the idea of crime, composing a universe with innumerous murderers, victims, detectives and spies. The purpose of this paper is to dive into this writing of dissolution and transgression, having as zero ground the poem "Nosso tempo", by Carlos Drummond de Andrade. The aim is to attempt, with the collision of the texts, to comprehend the ways with which the contemporary writes and is written in Leonardo Gandolfi's poems.

KEYWORDS: Brazilian poetry. Present time. The contemporary.

Recebido: 28/07/2013

Aprovado: 30/08/2013

Tiago Lanna Pissolati <tiagopissolati@gmail.com> é doutorando em Literatura na Universidade Federal de Santa Catarina. 


\title{
TEMPO DISSOLVIDO, TEMPO DO CRIME A ESCRITURA DO CONTEMPORÂNEO DE LEONARDO GANDOLFI
}

\author{
Tiago Lanna Pissolati
}

DE UM TEMPO DE DIVISAS

Quando Carlos Drummond de Andrade compôs o impactante poema "Nosso tempo", ele se colocou diante de certa ambivalência. Por um lado, o poeta dizia de um tempo localizado em seu próprio gesto - o da escritura. Por outro lado, ele lançava outro tempo próprio de um ato futuro - o da leitura. Tempo da escritura, tempo do poeta. Tempo da leitura, tempo do leitor. Dois tempos cada vez mais distantes, dois tempos crescentemente apartados. A fim de encerrar em uma palavra toda coexistência, Drummond faz uma amálgama, chamando os dois tempos de um só: tempo. Abraçou-o, então, com o plural: nosso tempo. Assim, entre o tempo do poeta e o tempo do leitor, surge um terceiro, resultado de seu encontro: nosso tempo, o tempo mútuo, o tempo do poema.

Dificilmente poderíamos chamar esse tempo-amálgama de Drummond de tempo presente. Afinal, trata-se de um tempo de coexistências: de um lado, o tempo do surgimento do poema, datado de 1945; de outro lado, os múltiplos tempos de cada leitura de seus versos, que se projetam para o futuro. Nesse sentido, o tempo do poema não é o presente - ou, ainda, não é apenas presente. "Nosso tempo" não é só agora. 
"Este é tempo de divisas, / é tempo de gente cortada", 1 anuncia a segunda parte do poema. Parte-se, assim, de um limiar: entre o agora da escritura e o agora da leitura, resta uma série de deslocamentos. Entre essas divisas, nunca permanecendo em um desses instantes, vivemos cortados.

Essa constatação de uma experiência deslocada do presente faz lembrar um relato do também poeta Octavio Paz. Muito embora tal experiência tenha se dado para Paz de forma gradual, ele recorda certo incidente que ocorrera em sua infância e lhe dera um primeiro sinal desse deslocamento: o encontro com uma fotografia de soldados norte-americanos, retornados da guerra, desfilando em uma avenida de Nova Iorque. Para o ainda jovem poeta, aquela guerra teria ocorrido em outro tempo - não agora, não aqui. "Eu me senti, literalmente, desalojado do presente", relata. ${ }^{2}$ Do sentimento de banimento de seu próprio tempo, segue uma crescente sensação de cisão. Octavio Paz, a partir daí, passa a pertencer à "gente cortada" drummondiana. Vive, no tempo, uma fratura.

Fratura que também pulsa nos versos de outro poeta. "Minha fera, minha era, quem ousa, / olhando nos teus olhos, com sangue, / colar a coluna de tuas vértebras?", indaga o poema $A$ era de Óssip Mandelstam, relembrado pelo filósofo Giorgio Agamben. Nos versos, o tempo ganha a forma de uma fera cuja coluna vertebral é fraturada. Para que os ossos sejam recompostos, é preciso soldá-los com sangue. Sangue do poeta, que vive a cisão do tempo, mas traz em suas veias aquilo que pode salvá-lo. "O poeta, enquanto contemporâneo, é essa fratura, é aquilo que impede o tempo de compor-se e, ao mesmo tempo, o sangue que deve suturar a quebra", afirma Agamben. ${ }^{3}$ Nesse ponto, os poetas se encontram: assim como Mandelstam, Octavio Paz é a fra-

1 ANDRADE, Carlos Drummond de. Nosso tempo. In: A rosa do povo [1945]. 25. ed. Rio de Janeiro: Record, 2002, p. 39.

2 PAZ, Octavio. La búsqueda del presente. In: Inti. Revista de literatura hispánica. Providence: Department of Modern Languages - Providence College, v. 1, n. 32/33, otoño 1990, p. 6. Tradução minha.

3 MANDELSTAM, Óssip. A era [Trad. Haroldo de Campos]. In: Poesia russa moderna. Nova antologia. Trad. Augusto de Campos e Haroldo de Campos, Rev. Bóris Schnaiderman. 2. ed. rev. e amp. São Paulo: Brasiliense, 1985, p. 152. 
tura temporal que vive. Assim como Paz, Carlos Drummond de Andrade é, também, a solda que pode saná-la: poesia.

Mandelstam, Paz e Drummond, vivendo a experiência de deslocamento do presente, são o tempo cortado. Cientes desse deslocamento e dispostos a saná-lo com seus versos, são também a cola que pode reatar o tempo. Ao encarar tal paradoxo em seus escritos, os poetas se colocam, de formas diversas, diante de um presente que escapa. Direcionam o olhar a um tempo que parece apenas se afastar. Ainda, eles são o próprio tempo - e são, também, o afastamento que se dá.

Por isso o presente que a contemporaneidade percebe tem as vértebras quebradas. 0 nosso tempo, o presente, não é, de fato, apenas o mais distante: não pode em nenhum caso nos alcançar. 0 seu dorso está fraturado, e nós nos mantemos exatamente no ponto da fratura. Por isso somos, apesar de tudo, contemporâneos a esse tempo. ${ }^{4}$

A essa modalidade única de afastamento, proveniente do paradoxo de ser a quebra e a sutura, o veneno e o remédio, Giorgio Agamben denomina ser contemporâneo. Trata-se de um posicionamento único diante do próprio tempo, que vive em suas fissuras e esforça-se para reatá-las. Ser contemporâneo, segundo o filósofo, é ver o próprio tempo não como algo presente e consistente, mas como algo que se aparta a qualquer ímpeto de aproximação. É ter uma experiência do tempo que, tão logo se oriente para dentro dele, nos coloca de fora, de forma que dali o contemplemos.

À possibilidade de aproximação, o contemporâneo responde com afastamento. À tentativa de segurar nas mãos o próprio tempo, o contemporâneo diz da impossibilidade de alcançá-lo. A experiência do contemporâneo, assim, aproxima-se a uma experiência de desencontro. Uma experiência de não pertencer ao próprio tempo; de não viver um tempo inteiro; de ver, no próprio tempo, uma impropriedade.

Tendo um olhar direcionado não necessariamente a um tempo presente -

4 AGAMBEN, Giorgio. 0 que é o contemporâneo? In: $O$ que é o contemporâneo? e outros ensaios. Trad. Vinícius Nicastro Honesko. Chapecó: Argos, 2009, p. 65. 
de ordem cronológica - mas ao que aqui, junto com Agamben, chamamos contemporâneo, vemos surgir uma nova série de poemas, cuja escrita evidencia e sutura a fratura do tempo: o livro $A$ morte de Tony Bennett, de Leonardo Gandolfi ${ }^{5}$. A escolha da obra, sobre a qual a partir de agora nos deteremos mais longamente, não se deve apenas à sua publicação recente, datada de 2010; trata-se de um conjunto de poemas em que os efeitos do contemporâneo se mostram com vigor notável. Passemos, agora, a olhar para o primeiro desses efeitos: a experiência do tempo como perda.

DE UMA HORA ESMIGALHADA EM PÓ

Um dos primeiros poemas dispostos em A morte de Tony Bennett já adianta o tema que atravessará toda a obra. Em "As estrelas no céu não querem dizer nada para você, elas são um espelho", os versos armam a cena do assassinato de um jovem tenente por um espião. Há, certamente, algum teor narrativo no poema; no entanto, as palavras dão a impressão de buscar um estado de suspensão do tempo em que as ações são descontinuadas e prevalece o instante. Do momento em questão, restam alguns instantâneos: as três cravadas de canivete nos rins do oficial, o arrastar de seu corpo pela areia da praia e a derradeira ação do assassino, que contempla, sob a luz da lua, o seu relógio.

A primeira estrofe do poema leva o leitor a supor que se trata de uma micronarrativa ("Martin Rivera segurou o tenente / pela gola da túnica e, mão direita, / empurrou o canivete rins adentro. / 0 jovem oficial soltou um grito, largou / a pistola, mãos trêmulas, à altura do peito."). ${ }^{6}$ Entretanto, a cena armada pouco a pouco vai dando lugar a uma palavra que não narra, mas pausa. A ação se dissolve enquanto o tempo entra em suspensão. "Cada um abandona o que pode e as horas / se descolam por generosidade ou fastio"7:

5 GANDOLFI, Leonardo. A morte de Tony Bennett. Rio de Janeiro: Lumme Editor, 2010. As demais referências indicam os títulos e páginas dos poemas.

6 As estrelas no céu não querem dizer nada para você, elas são um espelho, p. 13.

7 Ibidem, p. 13. 
generoso ou fastidioso, esse descolar das horas se afirma sobre o tempo da ação, ao passo que o poético cresce diante do narrado. Não seria surpreendente que restasse, ao fim desse processo de dissolução e suspensão, apenas o olhar para um relógio: "Na luz que a lua permitia, consultou o relógio". 0 poema se encerra, então, com algo de revelador e misterioso: "tinha ido se sentar nas pedras quando / finalmente compreendemos o que estava em jogo." ${ }^{8}$ Com o tempo suspenso e a ação dissolvida, permanece o que importa: a poesia.

Permanece uma poesia em que toda a cena parece se dissolver junto ao tempo. Vivem, fora de toda cronologia, assassino, corpo da vítima e, curiosamente, um relógio. Os momentos retirados da ação e construídos em suspensão pelo poema constituem imagens. Imagens que não são pregressas, que não são sinais de um porvir, mas que se colocam diante dos olhos do leitor como sintomas de algo que, entre o ontem e o amanhã, está de fora: "A dignidade das imagens, / sabíamos, crepita num lugar de difícil localização / entre o passado e os dias futuros. / É claro, naquela noite não seria diferente."9

Nas palavras de Gandolfi, o que resiste em algum lugar perdido entre passado e futuro é o que dá a dignidade das imagens. Digna, de certa forma, é sua condição ambígua: as imagens se perdem entre dois tempos, mas estão também fora deles. Se indagado sobre o que tem essa suspensão do tempo a ver com dignidade, nosso poeta (ou o assassino, ou o corpo, ou o relógio contemplado) poderia responder: estar perdido no transcorrer das horas e, portanto, fora do tempo, é a melhor forma de pertencer a ele. Ou, nas palavras de Agamben:

Pertence verdadeiramente ao seu tempo, é verdadeiramente contemporâneo, aquele que não coincide perfeitamente com este, nem está adequado às suas pretensões e é, portanto, nesse sentido, inatual; mas, exatamente por isso, exatamente através desse deslocamento e anacronismo, ele é capaz, mais do que os outros, de perceber e apreender o seu tempo. ${ }^{10}$

\footnotetext{
8 Ibidem, p. 14.

9 Ibidem, p. 14.

10 AGAMBEN, Giorgio. 0 que é o contemporâneo?, op. cit., p. 58-59.
} 
Ao compor um poema que dá sinais de construir uma narrativa para só então dissolvê-la em instantes de suspensão, Leonardo Gandolfi realiza uma escritura do tempo. Não necessariamente de uma poesia do agora, do instante presente, do momento atual, mas de uma série de imagens que, justamente por se expulsarem de seu tempo, são contemporâneas.

Em outro poema, "Estou dez anos atrasado", o mesmo tema: um assassinato. Nesses outros versos, mais um instante se decompõe em imagens: um homem, ao caminhar, olha para trás e vê seu assassino. Enfim, um tiro o mata. Mais uma vez, a escrita opera pela decomposição da cena e pela suspensão do tempo. No entanto, coloca-se aqui algo de dúvida acerca do estar-aí daqueles que são narrados. "Posso perfeitamente estar aqui, / é uma questão de referência.", afirma o poeta nos primeiros versos. "Perfeitamente poderia estar aqui, disse, / mas nada disso vale muito a pena. / Um passo e pronto, nunca achei que fosse você.", parece dizer o homem prestes a ser abatido. ${ }^{11}$ Nos versos do poema, existir ou não naquelas condições, naquela disposição, naquela cena, é "questão de referência". Nos últimos versos, por fim, como se a dissolução do tempo e da narrativa operada pelo poema tornasse tudo uma questão de perspectiva ou combinatória, assassino e vítima parecem poder trocar de papéis: "Ele ainda é seu assassino. Um instante, / não foi você quem atirou?". ${ }^{12}$

Ainda no poema em questão, a decomposição de uma suposta cena narrativa em imagens faz com que o tempo se desencaixe. A partir do título do poema - "Estou dez anos atrasado" - a cena de assassinato parece ser também lugar de desencontro com o tempo. Se estar atrasado é não ser capaz, por um momento, de fazer coincidir o tempo do eu com o tempo das coisas, estar dez anos atrasado é fazer com que essa não-coincidência se estenda para além dos relógios. Nesse quadro, resta saber de quem é o atraso: se da vítima, que já deveria ter sido abatida há dez anos; se do assassino, que há muito deveria tê-la encontrado; ou, ainda, se do poeta, cujos versos insistem

\footnotetext{
11 Estou dez anos atrasado, p. 21.

12 Ibidem, p. 21.
} 
em não encontrar o momento do agora.

Para além da noção de desencontro, a ideia do atraso traz em si um quê de movimento. Por um lado, o movimento de um passado em direção a um presente perdido: aproximação. Por outro lado, o deslocamento do presente rumo a um tempo que já foi: afastamento. Aproximação, afastamento - duas nuances de uma relação com o tempo que é, acima de tudo, não coincidente.

É essa mesma relação antitética - que, em nossa perspectiva, não é de forma alguma paradoxal - que surge no poema "A passagem secreta". Nesses outros versos, uma matéria narrada pouco se estrutura. Pulsa, nas palavras, a "substância das imagens". ${ }^{13}$ Como em um filme hollywoodiano de ação dissolvido e recombinado, aqui surgem carros acelerados, uma malha de estradas, cartas de baralho, quartos de hotel, o sol. São imagens quase despersonalizadas, cenas sem ação ou sujeito. 0 poema constrói-se, assim, como uma história subtraída de eventos e personagens, em que restam lugares e objetos, assim como um ou outro sujeito oculto. Em primeiro plano, apenas o movimento puro, o deslocamento por si só, a aceleração: “A velocidade, quem sabe, uma maneira / de chegar mais perto disso. Aproximação. / Afastamento." 14

Aproximação, afastamento: as palavras se repetem e se espalham ao longo do poema, como um refrão diluído que diz de uma relação da escrita com o (seu?) tempo. Aumentar ou diminuir a velocidade do olhar e das palavras, nesse sentido, é buscar uma espécie de ajuste que torne possível ver o tempo e, assim, vivê-lo. Ao inscrever a velocidade no poema, Gandolfi estrutura uma relação com o tempo - uma relação que se coloca de fora dele (afastamento) e, assim, sente o seu pulsar (aproximação). Uma relação contemporânea.

Uma relação que vê, com a clareza possível, a inapreensibilidade do tempo. Se pertencer ao próprio tempo não é coincidir com ele, como nos relembra Agamben, a experiência do contemporâneo se estrutura a partir do inapreensível. 0 tempo se torna esse objeto que não se pode atingir. 0 presente vive

\footnotetext{
13 A passagem secreta, p. 32.

14 Ibidem, p. 32-33.
} 
como esse momento sempre buscado e nunca encontrado. Resta, com o tempo, uma relação que vive da perda e do escape: aproximação, afastamento. Nunca o toque. Nunca o encontro pleno. Nunca o ponto de chegada.

Por isso, o momento nunca traz o instante decisivo do encontro. Por isso, encontramo-nos sempre a alguma distância daquele ponto em que esse objeto - chamemo-lo de tempo, instante ou presente - se revela em sua plenitude. Porque é sempre cedo demais. Ou porque é sempre tarde demais. "Agora é só um pouco cedo demais", diz Gandolfi. "Porque a leitura com automóveis / tem uma só direção — depois."15

Em uma leitura que é sempre depois, estamos todos dez anos atrasados. Em um tempo que é um pouco cedo demais, estamos todos desencontrados do momento. No entanto, não adianta apressar o passo ou pisar no acelerador: "Por mais que corra / estarei sempre no meio do caminho". ${ }^{16}$ Afinal, ali, sempre mais adiante, encontra-se o que tanto perseguimos: tempo. Nesse cenário em que o alcance ou o encontro está fora de causa, tornamo-nos leitores desse objeto perseguido. Leitores de algo que, muito embora nos chame ao agora, coloca-se sempre mais além. Leitores de um texto-tempo inalcançável e inapropriável. Leitores do tempo.

$\mathrm{Na}$ "leitura com automóveis" orquestrada por Gandolfi, a velocidade faz mostrar algo que se esconde sob a máscara do cronológico: o contemporâneo, o nosso tempo, tem suas exigências que desconhecemos. "Tudo parece tão intuitivo / que a gente mal percebe as demandas / do nosso século"17, lembra o poema. Entre aceleração e lentidão, entre atraso e adiantamento, entre a experiência de um tempo que corre até se perder e outro que se achata até se plasmar, o poeta parece perder a capacidade de ouvir o próprio tempo. Nesse ponto, talvez Gandolfi completasse o verso de Mandelstam traduzido por Haroldo de Campos: Minha era, minha fera, quem ousa escutar teus grunhidos?

\footnotetext{
15 Ibidem, p. 33.

16 Ibidem, p. 32.

17 Ibidem, p. 33.
} 
A conjectura, de fato, não parece distante do que escreve Gandolfi. É em outro poema, não por acaso intitulado "Cronologia”, que o poeta dá sinais de ouvir desse tempo-fera, dessa era-animal, não mais que grunhidos indiscerníveis. No texto, após realizar uma espécie de balanço da própria vida, o poeta conclui: “Nossa canção / embora solitária e cheia de paz / é uma só canção e, cante o que cantar, / ouviremos apenas os ruídos deste / que tem sido apesar de tudo o nosso tempo." 18 Gandolfi, assim, coloca-se diante de um tempo que pode até ser nosso tempo - mas que o é apesar de tudo. Mais uma vez, o contemporâneo: um tempo apesar de. Um tempo que, longe de som e canto, é ruído, grunhido. Um tempo que só podemos ouvir em frações dissonantes.

Na poesia de Gandolfi, nosso tempo é tempo em que as horas se descolam. É tempo em que estamos dez anos atrasados. É tempo de aproximação e afastamento. É tempo apesar de tudo. Como em "Nosso tempo" de Drummond. Tempo de partido, de homens partidos, de divisa, de gente cortada. Tempo em que "a hora pressentida esmigalha-se em pó na rua". ${ }^{19}$ Nosso tempo, o tempo de Drummond e Gandolfi, é tempo de perda e desencontro. É contemporâneo.

\section{DAS PALAVRAS QUE APENAS QUEREM EXPLODIR}

Destes dias, destes anos, desta era que "tem sido apesar de tudo o nosso tempo", ouvimos ruídos. Deste misterioso animal, desta fraturada fera, só escutamos um som gutural. Algo que, no poema de Mandelstam, "jorra da garganta das coisas". ${ }^{20}$ Nosso tempo, nossa era, nossa fera - de sua desconhecida sinfonia, só encontramos frases soltas, sons estranhos. De sua tão pulsante escrita, só lemos partes indecifráveis. Do nosso tempo restam os fragmentos.

\footnotetext{
18 Cronologia, p. 47.

19 ANDRADE, Carlos Drummond de. Nosso tempo, op. cit., p. 38.

20 MANDELSTAM, Óssip. A era, op. cit., p. 152.
} 
Retornemos a Drummond: "Tenho palavras em mim buscando canal, / são roucas e duras, / irritadas, enérgicas, / comprimidas há tanto tempo, / perderam o sentido, apenas querem explodir". ${ }^{21} 0$ tempo do poeta mineiro - que é, ainda, nosso - exerce uma insondável força de compressão sobre o verso, a palavra, a letra. Longe de ser válvula de escape de um sentimento que pede para ganhar o papel, o poema torna-se bomba, pronto para esvaziar o que diz a palavra e fazer dela um sem-número de estilhaços.

Não seria diferente no tempo de Gandolfi, ou ainda, no tempo apesar de que Gandolfi escreve. Trata-se, afinal de contas, de um tempo em que importam o ruído, o desfazer das horas, os instantes cortados, as imagens que, longe de um todo, têm substância porque são partes. 0 poema-bomba de Drummond (bomba-relógio, há que se dizer), encontra uma série de semelhantes na poética de Gandolfi - uma poética, acima de tudo, de restos.

Isso fica evidente logo na primeira leitura de $A$ morte de Tony Bennett, quando nos deparamos com uma série de imagens que nos remetem a um tema criminal-detetivesco. Nos poemas concentrados na primeira parte do livro (intitulada "Espiões em apuros"), deparamo-nos com um sem número de assassinos e vítimas, investigadores e espiões, armas fatais e cenas de crimes. Em "O lençol”, o corpo da vítima e um lençol compõem a cena do crime. ${ }^{22}$ Em "ODPIS", surge a curiosa anedota de um escritor que matara sua mulher e o amante e usara o crime como motivo de um livro. ${ }^{23}$ Já "O bosque" traz um misterioso diálogo entre uma mulher prestes a ser morta e seu suposto executor. ${ }^{24} \mathrm{Em}$ "Mercado negro", o poeta narra sua prisão enquanto portava um livro surrado nas mãos. ${ }^{25}$

"O último caso do inspetor", por sua vez, atrai a nossa atenção por conglomerar uma série de elementos do universo policial em um tempo que é de latência e espera. Nesse tempo, "O lugar do crime não é ainda lugar do crime”,

\footnotetext{
21 ANDRADE, Carlos Drummond de. Nosso tempo, op. cit., p. 39.

220 lençol, p. 19.

23 ODPIS, p. 24.

240 bosque, p. 25.

25 Mercado negro, p. 27.
} 
"O assassino não é ainda assassino", "A vítima não é ainda vítima”, "A testemunha não é ainda testemunha" e "A arma do crime não é ainda arma do crime". ${ }^{26}$ Agora eles ainda são, respectivamente, um quarto em penumbra, um caixeiro-viajante, uma jovem mulher, um inspetor ousado e um abajur de bronze que aguardam, pacientemente, a realização desse crime-potência. Mas não ainda.

Nesse universo poético construído em torno de assassinos e investigadores, crimes e inquéritos, somos nós, leitores, que acabamos por assumir o lugar de detetives. Afinal, são os detetives que procuram os rastros, os vestígios, os restos do crime que já ocorreu, a fim de neles encontrarem indícios, chaves, respostas. Como leitores-detetives, buscamos, nos poemas de Gandolfi, os fragmentos e ruídos de um tempo que, apesar de nosso, nós não alcançamos. Não ainda.

Nossa orientação detetivesca já é dada no primeiro poema, "Desaparecimento de Agatha Christie": "Quando descobrir o que seu suspeito vai fazer / é sua obrigação se antecipar a ele, / chegar ao local antes que o crime aconteça." 27 Arma-se um cenário em que nós, leitores, nos tornamos investigadores. 0 poeta, por sua vez, pode se tornar suspeito. "Se quiser descobrir o que ele está tramando / ou pensando será melhor persegui-lo. / Se possível entre o simultâneo e o repetido.", prossegue o poema. Eis o que se espera de um leitor-investigador: que sejamos capazes de fazer de nossa leitura uma série de antecipações; que possamos perseguir o poeta e que, se possível, o façamos no que ele incorre de repetição e simultaneidade.

No entanto, cabe indagar qual seria o crime desse poeta suspeito. Que espécie de transgressão se manifestaria em suas repetições? 0 que, em seu fazer, incorreria como simultâneo? Afinal, qual seria o crime de Gandolfi? Arriscamos, aqui, uma resposta: o crime é sua escrita.

A escrita de Gandolfi é crime por construir-se em torno de uma impropriedade: o tempo. Há que se pensar que, para todo detetive, o tempo do

\footnotetext{
260 último caso do inspetor, p. 38.

27 Desaparecimento de Agatha Christie, p. 11.
} 
crime é o tempo que se busca, com todo esforço, reconstituir. 0 crime, esse evento não presenciado, esse fato não testemunhado pelo investigador, é um momento inatingível. Nesse sentido, o crime se dá em um tempo que não pertence ao detetive, mas apenas ao criminoso. 0 crime, para aquele que tenta desvendá-lo, estrutura-se em um tempo impróprio, um tempo de nãopertença, uma tempo do qual se está do lado de fora.

Dessa forma, ao erigir com a letra uma série de crimes, Gandolfi constrói uma esfera de impropriedade para os seus leitores. Esse poeta criminoso faz com que seus leitores-detetives busquem, a todo custo, reconstituir, restaurar, compreender uma série de eventos inatingíveis. 0 crime de Gandolfi pauta-se, assim, pela escritura de tempos que nós, leitores, não podemos alcançar.

Entretanto, há algo de muito mais criminoso no gesto da escrita desse poeta. Munidos de um olhar investigativo - olhar certamente já incentivado pelo primeiro poema - os leitores de A morte de Tony Bennett, ao passo que se deparam com os vestígios criminosos deixados pelo escritor em cada um de seus poemas, podem desenvolver certo estranhamento. Algumas imagens que são trazidas em substância pelos poemas podem chamar a atenção para uma semelhança com algo que, a princípio, se desconhece. Algumas palavras podem parecer, em certos momentos, objetos de repetição. Uma ou outra dicção pode soar, aqui, e ali, simultânea. Em suma: ao longo do livro, a poesia traz repetidas impressões de déjà $v u$.

E é com esse olhar que ao mesmo tempo estranha e reconhece, que o leitor detetivesco contemporâneo, o leitor investigador do nosso tempo, acessa sua mirada cibernética, sua lupa enciclopédica, passando a reconhecer algumas das marcas do crime do poeta. E então vem o momento da revelação do ato transgressor: ao longo dos poemas, dispostos das formas mais diversas, estão cópias, apropriações, colagens dos mais variados textos. Por fim, esse leitor pode concluir que nem tudo em A morte de Tony Bennett é de autoria de Gandolfi. Eis o crime do poeta.

Basta usar uma ferramenta virtual de busca para perceber que o título do poema "As estrelas do céu não querem dizer nada para você, elas são um 
espelho" é, na verdade, uma tradução de dois versos da canção “I don't want to talk about it", cantada por Rod Stewart: "And the stars in the sky don't mean nothing / To you, they're a mirror". 0 título de outro poema já mencionado aqui, "Estou dez anos atrasado", é também título de uma canção dos anos setenta de Erasmo Carlos e Roberto Carlos. 0 diálogo no poema "O bosque" é parte do filme $O$ estranho, de Orson Welles. 0 primeiro poema da obra, "Desaparecimento de Agatha Christie", faz menção a um real desaparecimento da escritora britânica por 12 dias, que ainda é circundado de mistério. Esses são apenas alguns exemplos das dezenas de cópias, apropriações, repetições e simultaneidades que o poeta realiza em A morte de Tony Bennett. ${ }^{28}$

É importante ressaltar, contudo, que o crime de Gandolfi nem de longe pode caracterizar plágio. Afinal, não se trata de mera cópia. 0 que o poeta realiza ao longo de seus textos é um procedimento (criminoso, ainda) muito mais sagaz. Ao tomar para a sua poesia esses trechos, retalhos, fragmentos dos textos do mundo, ele dota esses vestígios de uma força nova. Repetidas, simultâneas, as palavras não significam o mesmo. Elas diferem, transformamse, ganham uma vida outra. Compõem imagens diversas - em substância chegando até mesmo a respirar com independência. Tais palavras, versos e trechos se dispõem a novos significados. Talvez, passem até despercebidas a leitores que não aceitaram o convite à leitura detetivesca, não deixando, ainda, de existir com força própria. Porque essas palavras-resto, esses versos-vestígio, esses textos-fragmento são estilhaços de uma explosão. Explosão criminosa, sim, mas explosão criadora.

Nesse sentido, se o primeiro poema da obra pede que persigamos esse poeta-suspeito e que, enfim, busquemos os vestígios de seus crimes entre suas repetições e simultaneidades, ele afirma que é possível que encontremos, na experiência criminosa de uma apropriação explosiva de palavras, uma experiência da potência criadora. "Pistas falsas, velocidade, solidão. Atrás dele / não para pensar como ele, mas por ele — / me perder onde se

28 Cf. PUCHEU, Alberto. Apoesia contemporânea. Manuscrito, para um compêndio minucioso — digno de Poirot e Dupin — das apropriações de Gandolfi realizadas na obra. 
perdeu, parar onde / parou, ver o que viu." 29 Ao seguir os passos criminosos de Gandolfi, podemos nos perder exatamente ali, onde o poeta se perdeu. Podemos encontrar as palavras perdidas que ele explodiu para, então, recriar. Ali, então, podemos ver o que ele viu.

"Comprimidas há tanto tempo, / perderam o sentido, apenas querem explodir", diz o poema de Drummond. 0 crime de Gandolfi - esse crime da explosão das palavras - é executado em parceria com o tempo. Tempo que comprime os textos, tempo que esvazia as palavras de seu sentido original, tempo que as explode e permite que se faça uma poesia de estilhaços. Uma poesia-bomba.

Não por acaso, um dos textos-estilhaço de $A$ morte de Tony Bennett é justamente um verso do "Nosso tempo" de Drummond: "0 espião janta conosco" torna-se título de um de seus poemas. Título-chave para compreender essa poesia que, sujeita ao tempo, explode as palavras e as reconfigura com fôlego novo. Essa poesia que, repleta de espiões, assassinos e vítimas, faz com que nos tornemos detetives em busca de vestígios, rastros e restos de um tempo inapropriável: o tempo do crime.

Na figura do "o espião [que] janta conosco", não há nada de mais contemporâneo. Contemporâneo é perceber que, entre nós, há esse ser estranho, essa palavra estranha, esse algo de estranho que nos remete para fora. Contemporâneo é notar que, em meio ao familiar, há algo que gira em falso. Contemporâneo é olhar com desconfiança para esse homem que está aqui e agora, mas que aqui e agora não pertence. Reconhecer, entre o familiar, o estranho. Encontrar, no estranho, o familiar. Contemporânea é não só a escritura de Gandolfi, mas a experiência de leitura de seus poemas tão estranhos, tão familiares.

O espião que janta conosco é esse estranho que Drummond reconhece e Gandolfi reencontra. Esse familiar que Drummond escreve e Gandolfi copia. Esse tempo que Drummond comprime e Gandolfi explode. Esse estranho familiar que é, apesar de tudo, nosso tempo.

29 Desaparecimento de Agatha Christie, p. 11. 